
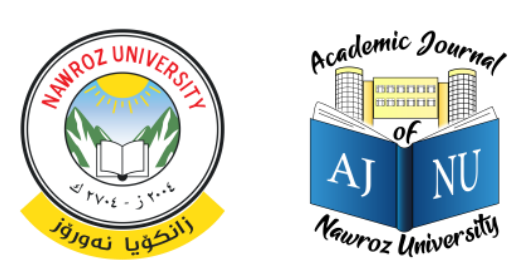

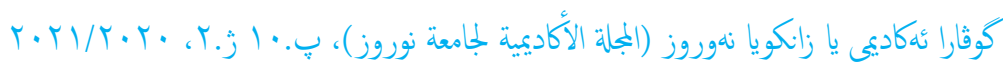

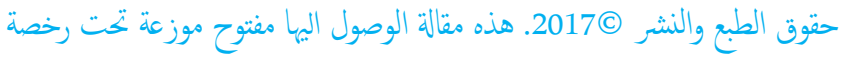
e-ISSN: 2520-789X ،CC BY-NC-ND 4. 0.

https://doi.org/10.25007/ajnu.v10n2a1010

\title{
البطالة وأثرها على معدلات الجريمة - في إقليم كورستان العراق
}

\author{
م.م. دلكش أحمد محم، كلية الإدارة والاقتصاد - جامعة نوروز ، أقليم كوردستان العراق
}

تتعرض هذه الدراسة لبيان العلاقة بين معدلات الجريمة وارتباطها بمعلات البطالة في إقليم كوردستان العراق ، ومن المعروف جغرافيا أن إقليم كوردستان يقع بيئة إقليمة غير مستقرة أمنيا، وتجدر

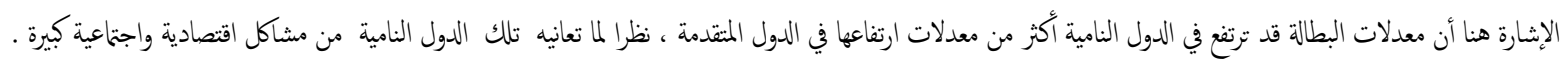

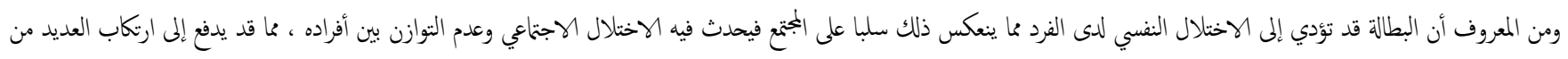

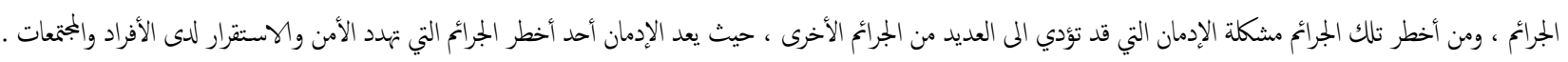

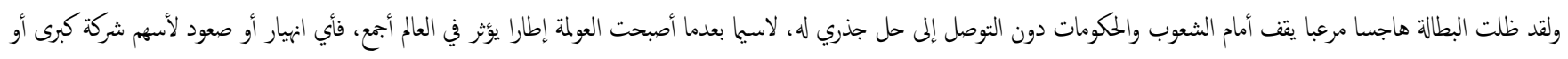

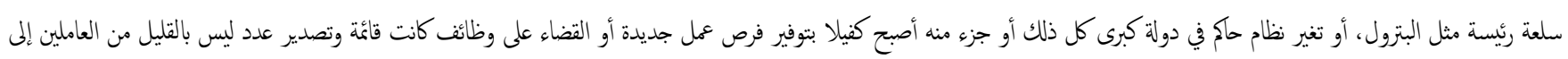
أعداد البطالة. .

الكلمات المثتاحية: معدلات البطالة، معدلات الجرية، إقليم كورستان.

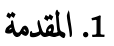

وأما في هذه الآونة فقد تأثر الإقليم مثل بقية أنخاء العالم بتبعات انتشار فيروس كورونا، فقد أشارت منظمة السلام والحرية إلى ارتفاع نسبة البطالة في الإقليم من 20\% إلى 44\% جراء تفشي فيروس كورونا وأكدت أن نحو 200 ألف عامل

$$
\text { فقدوا وظائفهم بسبب الأزمة. }
$$

من خلال هذا الطرح تنكشف لنا صورة واقع البطالة في إقليم كودستان العراق، فالبطالة في حد ذاتها خطر مهدد استقرار وتقدم البجتمعات، والبطالة جريمة تقتل آمال الأم وتهدر طاقة الشباب، وتضعف الأنظمة الحاكة وتفقدها مصداقيتها أمام

الشعوب، وتؤدي البطالة إلى تدني معدلات المعيشة بصفة عامة. وهناك ارتباط وثيق بين البطالة ومعدلات الجريمة، فالبطالة تؤدي إلى اختلال في الحلالة النفسية لكثير من الشباب، وهذا الاختلال يؤدي في كثير من الأحيان إلى إدمان المخدرات، وهذا الإدمان يفتح الباب على مصراعيه لحدوث الجرائم المتنوعة من السرقة القتل والاغتصاب الجنسي، وغيرها. فالبطالة في الغالب تؤدي إلى ارتفاع سن الزواج لدى الشباب إلى مستويات خطيرة فهنم من يثأخر حتى منتصف الثلاثينات من عمره. وأثبتت دراسات كثيرة ارتباط وثيقا بين البطالة وارتفاع معدلات الجريمة في كثير من دول العالم، وفي هذا البحث سيتم استقصاء ارتباط معدلات الجريمة في إقليم كوردستان العراق بعدل
من المسلم به عالميا أن سبة البطالة في أي دولة أو مدينة بالعالم، تخضع لعدة عوامل، منها المستوى التعليمي، والتزكية السكنية، والنشاط الاقتصادي للدولة، ومعايير الأمن، ومخرجات الأظظمة التعلمية. وإقليم كوردستان العراق مثل معظم الدول والأقاليم، وخاصة في الدول النامية والتي تزداد فيها نسبة البطلة بين الشباب، بل إن ما مر وما يمر به الإقليم من ظروف خاصة بسبب موقعه ، والذي يقع في بيئة إقليمة غير مستقرة ؛ مما يجعل من الظروف الاقتصادية ظروفا صعبة، حيث يتعرض الإقليم لاستضافة أعداد كيبرة من النازهين من ويلات الحروب والدمار حيث إن الإقليم يستضيف أكثر من 800 ألف من المحافظات العراقية الأخرى وربع مليون سوري، بل إن الإقليم

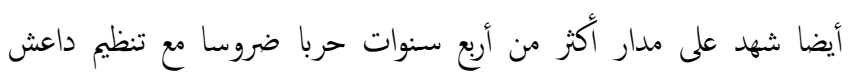
الإرهابي ما بين عاي 2014 و 2017، ولا شك أن كل تلك الظروف تؤثر تأثيرا

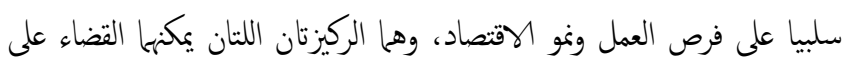

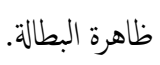
وقد صرح وزير التخطيط في إقليم كوردستان"علي سندي" أن معدل البطالة في عام 2017 وصل إلى 14\% بعدما كان 6.6\% في عام 2014، وأنه لا يزال يتذبذب صعودا وهبوطا ولو بشكل طفيف. (طبقا للموقع الإلكتروني: البطالة. 


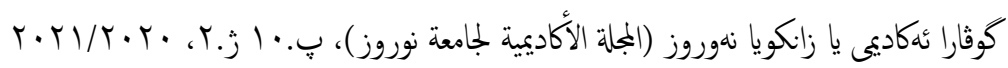

هناك العديد من المشكلات القائمة التي تتناج إلى المعالجة والتحليل لمعرفة الأسس التي قامت عليها ، ينطلق البحث من فرضية مفادها أن هناك علاقة طردية بين معدلات البطالة ومعدلات الجريمة في أقليم كوردستان العراق، فكلما ارتفت معدلات البطالة ارتغت على إثرها معدلات الجرائم المرتكبة ، وسوف يقوم الباحث بدراسة هذه الفرضية إنطلاقا من العلاقة بين البطالة ومستوى الجريمة في إقليم كوردستان العراق، وبالتالي فإنه سيعرف بصطلح البطالة وسيذك بعض أسباها ودوافعها ، ثم النتائج المترتبة عليها ، وسيناقش أيضا العلاقة بين البطالة

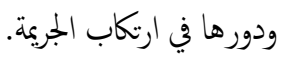

\section{1}

- تقوم هذه الدراسة على المنهج التحليلي، حيث يقوم الباحث بالحصول على البيانات الموثقة عن ارتفاع معدلات البطالة في الإقليم محل الدراسة ثم بدراسة و تحليل هذه البيانات طبقا للمنهج التحليلي ، الذي يسمح للباحث

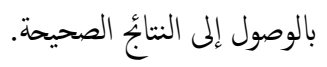

- - مسيقوم الباحث بالوقوف على أهم أسباب ارتفاع معدلات الجريمة والتي تنشأ عن البطالة ، ثم البحث عن سبل تفادي هاتين المشكلين من خلال محاولة إيجاد الطرق والوسائل المناسبة للحد من هاتين الظاهرتين ، اللتان

$$
\text { تؤثران سلبا على معدلات التنمية . }
$$

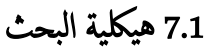

- - المبحث الأول: مفهوم البطالة والعوامل المؤثرة فيها والآثار المترتبة على

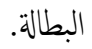
- - المبحث الثاني: معدلات البطالة والجريمة في إقليم كرردستان العراق قبل .2013 - - المبحث الثالث: معدلات البطالة والجريمة في إقليم كوردستان العراق في

- - المبحث الرابع: أثر انخفاض وارتفاع معدلات البطالة على الجريمة في إقليم

$$
\text { كوردسنتان. }
$$

2. المبحث الأول: مفهوم البطالة والعوامل الموثرة فها والآثار المترتبة على البطالة
تعد مشكة البطالة من أكثر المشكلات التي تؤرق العالم بشكل كير ، بل وينبثق عنها بعص المشاكل الكبرى ومن أهها مشكلة الجريمة التي تجوب العالم كله ، وقد تكون البطالة أحد أهم أسباها ، ومن المعلوم أن تلك المشكلة قد توثر سلبا على الفرد والمجتع ، وعلى الرغً من المحاولات الحثثية لثفادي هذه المشكلات ، إلا أننا قد نجد أن معظم الدول النامية ما زالت تعاني وبشدة من هذه المشكلة ، وهذا ما دفعنا للبحث في هذه المشكلة للوقوف على أساسياتها وتحديد السلبيات التي قد تنتج عن هذه المشكلة وقد حددنا فتزة زمنية معينة وحددنا إقليما معينا للبحث ، وهذا ما سيتضح معنا من خلال البحث .

\section{1 مشكلة البحث}

تزكز مشكلة البحث في إيجاد العلاقة الفعلية بين إرتفاع معدل البطالة في إقليم كوردستان العراقي وما يتزتب على هذه النسب المرتغعة من جرائم ومشاكل تتسبب في عدم الاستقرار وتهدد الأمن الوطني ، حيث أن الاستقرار الأمني يرتبط بالهدوء النسبي بين طبقات الجمتعع ، وفي حالة انعدام هذا الهدوء ووجود معدلات بطالة مرتفعة بين الشباب ، فسينج عن ذلك بالطبع تزايد في معدلات الجرائم ، حيث أن هناك تناسب طرديا بين المشكلة محل الدراسة والنتائُ المترتبة عليها ، ففي حالة ارتفاع معدلات الشباب الذين لايجدون العمل المناسب (ما يسمى بالبطالة) فإن هنالك بالضرورة إرتفاع أيضا في معدلات الجرائم التي يرنكها هؤلاء الشباب مما ينتج عنه الإنفلات الأمني في المنطقة بأسرها .

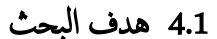

هيدف هذا البحث إلى لفت انتباه الحكومة إلى مخاطر البطالة، والتي تقضي على أي معدلات للنمية، بل يكننا القول إننا لن نشعر بوجود أي تنمية تتحقق في ظل ارتفاع معدلات البطالة، والتي بدورها تؤدي إلى ارتفاع معدلات الجريمة. وللقضاء على معدلات الجريمة المرتفعة، يجب التنبه إلى دوافعها الاجتمية والقضاء على هذه الدوافح حتى يتحقق الهدف إما بتقليل معدلات الجريمة إلى أدنى معدل مككن، أو بالقضاء عليها نهائيا، ولن يتحقق ذلك إلا بالقضاء على ظاهرة البطالة أو التقليل منها قدر الإمكان. وأيضا ضرورة تشجيع القطاع الخاص وتنميته ليكون جنبا إلى جنب مع القطاع العام في استيعاب الطاقة العالية من الشباب و تنبيه المسؤولين إلى ضرورة توفير قروض ميسرة للشباب لإقامة مشروعات صغيرة. 


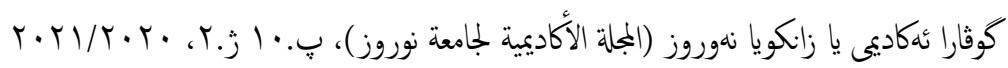

الانتخابية لكثير من قادة الأنظمة السياسية في العالم أبمع على تقديم وعود براقة وآمال جاذبة للناخبين بالقضاء على البطالة، ولكن ظلت البطالة هاجسا مرعبا يقف أمام الشعوب والحكومات دون التوصل إلى حل جذري له، خصوصا بعدما أصبحت العولمة إطارا يؤثر في العالم أبمع، فأي انهيار أو صعود لأسهم شركة كبرى أو سلعة رئسة مثل البترول، أو تغير نظام حاكم في دولة كبرى كل ذلك أو جزء منه أصبح كنيلا بتوفير فرص عمل جديدة أو القضاء على وظائف كانت قائمة وتصدير عدد ليس بالقليل من العاملين إلى أعداد البطالة، ومن العوامل الرئيسة في الثأثير على معدلات البطالة سلبا أو إيمابا في أي مكان (الإسكوا - الأم

(30-20 - المتحدة 2015

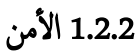

انضباط النواحي الأمنية، يشجع فرص الاستثمار، ويجذب المستثمرين وبالتالي تُخلق فرص عمل جديدة، والمثل بالمثل فضياع الاضضباط الأمني ووجود الحروب

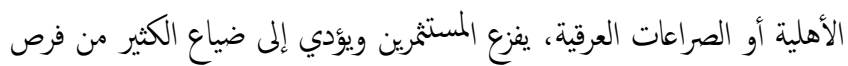

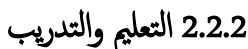

عندما يكون التعليم متطورا ومتناسقا مع سوق العمل؛ تكون البطالة في أضعف صورها، حيث يحتوي سوق العمل دائما أي عالة مدربة، وأما التعليم غير المتطور أو ذو الخرجات الضعيفة أو غير المتناسق مع سوق العمل فهو يصدر مخرجاته

مباشرة لزيادة أعداد العاطلين.

- 3.2.2

بتتنع الاقتصاد المتنوع بمرونة كبيرة في اجتذاب العالة والقضاء على البطالة، وخاصة عندما يكون يتمد في جزء كير منه على الصناعة سواء كانت صناعات كبرى أو متوسطة أو صغيرة، فالصناعة يكنها استيعاب أعداد كيرة من العالة في كافة

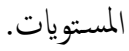

بينها الاقتصاد المحدود أو الذي يعتمد على الزراعة فقط فلا يمكنه استيعاب الأعداد الكبيرة التي تدخل إلى سوق العمل، ويعد عاملا ذا تأثير سلبي في القضاء على

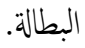

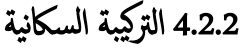

1.2 تعد البطالة ظاهرة اجتاعية واقتصادية، نشأت منذ زيادة أعداد السكان في مكان ما بالمقارنة برص العمل المتاحة في ذلك المكان ، ولقد ظهرت البطالة بعد ظهور الصناعة إذ لم يكن لها أي وجود في ظل الحياة الريفية والزراعية، كما يعد التطور التقني والذكاء الاصطناعي في هذه الآونة سببا أيضا في زيادة البطالة، نظرا لقيامه بكثير من همام البشر، ولها عدة تعاريف ومفاهيم منها: تعرف البطالة: بأنها عبارة عن تعبير يطلق على الأفراد الذين يعيشون بلا عمل؛

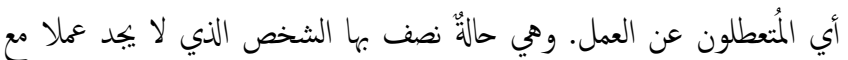
محاولته الدائمة في البحث عن عمل، يناسب ما لديه من مهارات. (عبد السميع 2008 - مشكلة البطالة في المجتمعات العربية). ومن التعريفات الأخرى للبطالة أنها وجود أفراد في الجمتع قادرين على العمل وسلكوا طرقأكثيرة للبحث عن وظيفة ما ولكنه لم يحصلوا على فرصة مناسبة لمم. وفيم يتعلق بالتزيبة السكانة، نجد أن البطالة تختص بفئة الشباب فقط أو تحديدا بالفئة العمرية لمن هم في سن العمل، من عر 18 عاما إلى 45 عاما، أما فيا يخص الأطفال وكبار السن فغالبا لا تشماهم إحصاءات البطالة، وذلك مؤشر إلى أن الأعداد الحتيقية للعاطلين عن العمل دائما ما تفوق ما يتم رصده من خلال المؤشرات الرسمية للادول والحكومات. (مجموعة من الباحثين والمؤلفين (1999) -

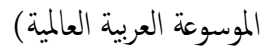
ومن خلال ذلك يتبين لنا أن هناك فئات كثيرة لا يتم احتسابها ضمن العاطلين

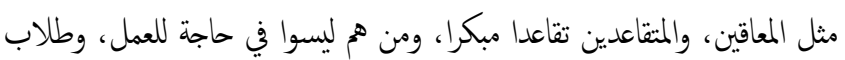
الجامعات والدراسات العليا، وأصحاب الأعال الموسمية والمؤقتة، ومن لا يحث عن عمل بسبب يأسه من اقتناص فرصة عمل، وهناك البطالة المقنعة، وهي أكثر انتشارا في البلاد النامية بصفة خاصة، ففي الكثير من الدوائر الحكومية نجد اكتظاظا كبيرا للموظفين الذين ليس لمم دور فعلي في العمل ويككن الاستغناء

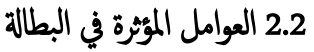

أخذت معظم الدول على عاتثها توفير فرص للعمل عن طريقها فيها يسى بالقطاع العام، وكانت الدول حتى بعد منتصف القرن الماضي بقليل تستطيع توفير هذه الخدمة للشعوب وخصوصا في الدول النامية التي كانت كثيرا منها تبدأ في إنشاء هيئات ودوائر حكومية بعد نيل استقلالها، بل اعتمدت كثير من الدعاية 


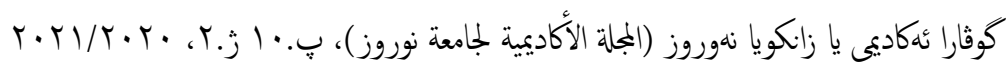

بوجوده لأنه يحصلون على عدد من الوظائف والتي كانت - في غير وجودهم ستذهب إلى المواطنين الأصليين.

\subsection{2 العمالة الأجنبية}

تعد العالة الأجنبية إحدى روافد زيادة أعداد العاطلين وزيادة نسب البطالة، ويلجأ كثير من أصحاب المصانع والشركات لاستقدام العمالة الأجنبية لأنها تكون أعرر وأرخص في النكلفة وأكثر انضباطا في العمل من العجلة الوطنية.

\subsection{2 الكوارث الطبيعية والجوايخ}

تعد الكوارث الطبيعية مثل الزلازل والبراكين والفيضانات والجفاف والجوائح المرضية والأوبئة أحد العوامل المؤثرة سلبا على تخفيض نسب البطالة، وخير دليل ما نشاهده حاليا من فقدان العديد من الناس لوظائفهم بسب جائحة كورونا.

$$
\text { (نفس المصدر - بتصرف) }
$$

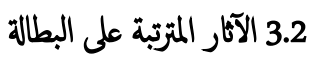

الآثار المتزتبة على البطالة عديدة ومتنوعة فهي أولا ذات تأثير سلبي على الفرد واليجتع، هذا التأثير لا يتوقف عن الأثر الاقتصادي خفسب، بل يتعداه إلى الأثر

$$
\text { النفسي والاجتاعي، لكل من الفرد والمجتع. }
$$

فالشخص الذي يفقد وظيفته يفقد معها مصدر دخاه القائم، ويتزتب على ذلك ضرورة بحثه عن مصادر بديلة، وقد تكون هذه المصادر من طرق غير شرعية، مما يؤدي إلى ارتفاع معدلات الجريمة بالتوازي مع ارتفاع نسب البطالة. تسوء الحالة النفسية للمتعطل عن العمل، مما يعرضه لإدمان المخدرات أو الكحوليات، وكذلك يكون عنيفا في تعامله مع كل من حوله سواء من أفراد أسرته او جيرانه أو كل من يتعامل معه، ويكون في الغالب يحتاج إلى مساندة نفسية

$$
\text { وعلاج نقسي. }
$$

زيادة نسب البطالة تؤدي إلى انخفاض الإنتاج، فكل زيادة في البطالة بنسبة 1\%

$$
\text { ينتج عنها نصص 2\% في الإنتاج. }
$$

فآثار البطالة لا تتوقف عند الجانب الاقتصادي فسب، بل لها آثار أشد ضراوة

$$
\text { على النواحي الاجتاعية والنفسية. }
$$

الجريمة: قد تؤدي البيئة غير المستقرة للمتعطل، وشعوره بالوحدة لابتعاده عن الجمتع الخارجي الذي يعيش فيه إلى ظهور الجريمة وتفشّيها بالمجتع، ولكن لا يعني هذا أنّ جميع المتعطلين هم أصحاب جرائم وأسبقيات، لكن البطالة، والفتر ،
التزيبة السكانية لأي ججمع هي كلمة السر في زيادة أو انخفاض نسبة البطلة، فالمجتمعات التي تصنف على أنها شابة نجدها في الغالب لا تعاني من البطالة، أما الجمتمعات التي تكون نسب الأطفال أو كبار السن فيها كبيرة فهي تعاني من البطالة.

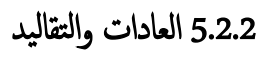
في كثير من الدول العربية وخاصة في المناطق ذات الطبيعة القبلية أو الريفية نجد هناك عادات وتقاليد تمنع عمل المرأة، وبالتالي يمثل النساء في مثل هذه الجمتمعات النسبة الأكبر من بين العاطلين عن العمل ويمثل ذلك إهدارا لقوة بشرية هائلة،

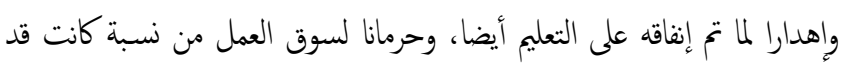
تشكل قيمة مضافة للاقتصادات الوطنية.

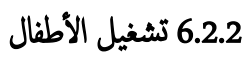
يعد تشغيل الأطفال الأقل من عمر خمس عشرة عاما انتهاكا صارخا لحقوق الإنسان والطفولة، ويلجأ كثير من أصحاب الأعال - في ظل غياب الرقابة الحكومية والمتابعة - لتشغيل الأطفال نظرا لانخفاض أجورهم مقارنة بالعالة الرسمية، ولذلك يعد تشغيل الأطفال عاملا مساهما في زيادة نسب البطالة.

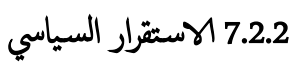
يعد الاستقرار السياسي في الدول عاملا عما في القضاء على البطالة، فكثير من الشعوب التي تمر بثورات أو فوضى جراء عدم الاستقرار السياسي يتوقف معها النشاط الاقتصادي وتتوقف عجلة الإنتاج مما يؤدي إلى زيادة أعداد العاطلين

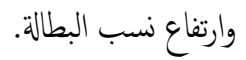

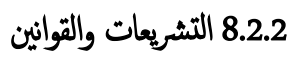
تعد التنشريعات والقوانين إحدى العوامل المؤثرة سلبا أو إيجابا في التأثير على نسب البطالة، فالدول التي تسن قوانين وأنظمة توفر الحماية الكاملة لحقوق العاملين هي الدول التي تستطع القضاء على البطالة بسرعة، وأما الدول التي لا تكون قوانينها تثثل حاية حقيقية لمصاح العحال أو لا تحقق الأمان الوظيفي لم فنجد أن العال في هذه الدول يعزفون عن العمل فيها، ولا يكون أماهم إلا خياران فقط إما السفر للعمل في دول أخرى أو الاضضام لصفوف العاطلين.

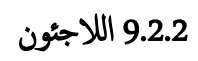

يمثل اللاجئون عبئا ثقيلا على الدول التي تستضيفهم سواء كانت تقيم لم خخيات

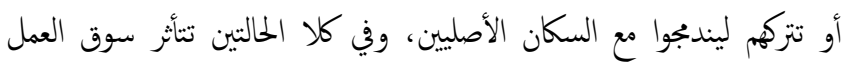




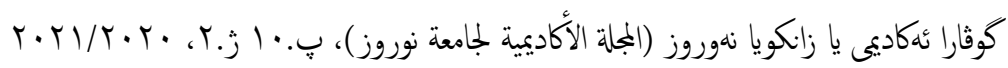

تعمل البطالة على تدمير العلاقات الأسرية وصلة القرابة وعزوف الشباب

$$
\text { عن الزواج. (البديري، 2015، 9 9). }
$$

كما أننا إذا أردنا أن نقارن بين علاقة معدلات البطالة بعمدلات الجرائم المرتكبة فإننا سنجد أن هناك العديد من الباحثين الذين ناقشوا هذه المعدلات في دراساتهم

تشير الدراسة التي أجراها أكرم وخان وطفيل (2012) أيضًا عن تزايد القتل في الشوارع والسطو والخطف بسبب البطالة. ركزت دراستهم على إبراز الشرور التي تسبيها البطالة، كما أظهرت الدراسة أن المحسوبية في السياسة أصبحت أحد أسباب البطالة، غالبًا ما يحرم الشباب من الحصول على وظائف على أساس الجدارة مما يؤدي إلى الإحباط والجرائم. يككن السيطرة على معدل الجريمة من خلال وضع سياسات عادلة في البلاد حتى لا يحرم أحد من حقه. يجب على

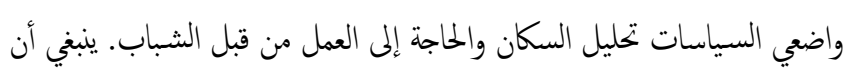
تعكس الخطط الوقتصادية للبلدان النامية بوضوح احتياجات العالة لشباها. خلاف ذلك ، لا يككن السيطرة على الجرائ.كما ركزت الدراسة على طلب النوع

$$
\text { المناسب من التعليم اللثباب حيث أنها ستوبحمم لاختيار المسار الصحيح. }
$$
وقد دراسة أفادت (Sanusi 2012) أن الناس سيحققون احتياجاتهم بأي وسيلة. وركزت على الطبيعة البشرية لتبية الاحتياجات، عندما يكون الشباب عاطلين عن العمل ومتاحين يتم تجنيدهم من قبل العصابات والجماعات التي تجعلهم يرتكبون جرائم غير قانونية وهجومية. كما ناقشت الدراسة أنه عندما يتخرج الطالب، فإنها لحظة فرح وسعادة ولكنها تتحول تدريياً إلى إحباط عندما لا يجد الشباب فرص عمل. ولتحقيق توقعاتهم واحتياجاتهم سيتحول الخزيجون العاطلون

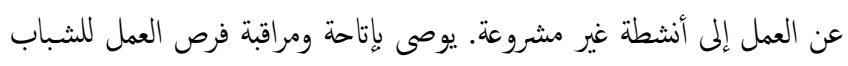
لمنعهم من شرور الإجرام والمخدرات.

\section{3. المبحث الثاني: معدلات البطالة والجريمة في إقليم كوردستان العراق قبل 2013 1.3 معدلات البطالة في إقليم كوردستان العراق قبل 2013} يقول المسؤولون في وزارة العمل بإقليم كوردستان، إن "الأزمة المالية وقدوم عدد كير من المهاجرين تسبب بتضاؤل فرص العمل للعال في إقليم كوردستان، فيا ارتغت نسبة البطالة إلى 13.53\%. وبحسب بيانات هيئة الإحصاء في إقليم
وانخفاض مستوى الاقتصاد العام تعتبر من أسباب وقوع الجرائم. (إخلاص فاضل

$$
\text { واخرون - } 2012 \text { - (24) (24) }
$$

4.2 الآثار الأجتاعية للبطالة

البطالة تؤدي إلى انخفاض فاعلية سلطة الأسرة بجيث لا تستطيع أن تقوم أو تمارس دورها في عملية الضبط الاجتاعي للأطفال. أضف إلى ذلك أن حالة البطالة عند الفرد يمكن أن تخلق اثارا سلبيا حيث يشعر العاطلون بالإحباط واليأس وعدم الاتماء للدولة، فتتنشر الجريمة بأنواعها، وتؤدي حالة النعطل الدائم والمؤقت عن العمل وما يصاحها من مشكلات اجتاعية وضغوطات اقتصادية على إصابة غالبية الشباب المتعطل عن العمل بحالة من الإحباط الشديد المزمن وحالة من عدم الثقة بالنفس وخاصة لدى الشباب حاملي الشهادات، مما يدفعهم هذا الشعور إلى النفكير جدياً بالانتقام من المجتع الذي يرفض منحهم فرصة العيش الكريم، وتحسين أوضاعهم الاجتاعية. ولها آثار اجتاعية تهدد عملية الاستقرار الاجتماعي من خلال تفشي الأعمال غير المقبولة اجتاعياً والتسرب من الدراسة وانتشار الأمية، وانتشار الجريمة، وخاصة لدى الشباب العاطلين عن العمل أذ سن تشير احدى دراسات البرنامج الإنمائي حول العراق الى ان 85\% من الجرائم التي تقع عند الفئة العمرية 10-24 سنة هي لدى العاطلين عن العمل (هاثم و آخرون، 2010، 87). ان معظم المعطيات المتوفرة عن مشكلة البطلة تشير الى أن مشكلة البطلة في تزايد سنة بعد أخرى، و أن المعالجات التي كان من المقترض ان تضع لهذه المشكلة لم تكن بمستوى الطموح ولا تعبر عن استراتيجية فعالة وهادفة الأمر الذي عقد هذه المشكلة وزاد من خطورتها. وفيما يلي أهم الاثار الاجتاعية التي تتركها هذه المشكلة على الصعيد الاجتاعي و يككن تلخيص هذه الآثار في النقاط التالية:

تعمل مشكلة البطالة على إضعاف عامل الولاء للدولة والوطن، وتراجع حالات التأييد والإسناد للقرارات المعلنة للدولة . تشكل البطالة عاملاً قوياً لدفع الفرد نخو الانراف وارتكاب الجرائم على اختلاف أنواعها مثل الإرهاب والخدرات وغيرها من الجرائم الأخرى لغرض

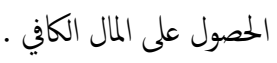




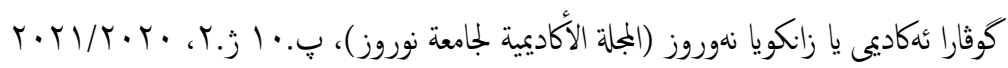

لا توجد مؤشرات أو إحصاءات رسمية تتبع معدلات الجرائم قبل عام 2013، وإن كانت المؤشرات والأخبار تتجه إلى نشر جرائم العنف ضد النساء وجرائم الشرف رتح

فقط.

ولا شك أنه قبل أن يتعرض الإقليم لموجات متتابعة من النازهين إليه من سوريا ومن أنحاء العراق المختلفة، هؤلاء النازحين من مناطق سيطرة داعش. فمن المؤكد أنه حينا تختني معلومات أو بيانات عن شيء ما، فإن ذلك يعني أنه إما

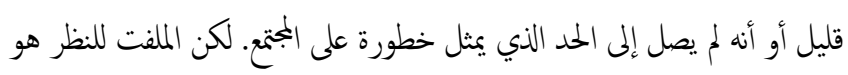
إدراج العراق على قائمة الدول الأكثر خطرا في غسيل الأموال في عام 2012، وهي جرائم تعد من الجرائم الدولية، ومن أسباهها النفوذ الخارجي لدول معينة داخل العراق ، وعدم سيطرة الحكومة المركزية على منافذ البلاد وموانيها، ووجود وكلاء لدولة إيران داخل العراق لتنظيم نهب ثروات العراق، هي جرائم بالطبع لا تعبر عن سلوكيات المواطن العراقي البسيط سواءكان في إقليم كوردستان أو في

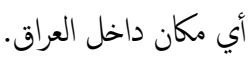
وكان أول تقرير لـ"مؤشر بازل لمهافة غسل الأموال" عام 2012 قد صنف العراق في المركز السادس بين أسوأ الدول في مجال مكافة غسل الأموال، وهو ما دعا الهحاد الأوروبي إلى وضعه في يوليو 2016 على قائمة الدول التي تثنقر إلى تطبيق المعايير الدولية. ورغ أن الاتحاد وفي بادرة حسن نية، عاد عام 2018 ورفح اسم العراق من قائمّه السوداء حتى مع احتلاله المركز الأول في تقرير مؤشر بازل لعام 2017 كأخطر دولة في مجال غسل الأموال، إلا أن الحكومة العراقية فشلت في استغلال هذه الفرصة لتحسين صورة البلاد عبر الخطو باتجاه تلبية انشغالات شركائا الدوليين .(مركز الإمارات للسياسات - مقال (إدراج العراق في اللائة الأوروبية للدول عالية الخخاطر في جرائم غسل الأموال - الأسباب

والتداعيات)

\section{4. المبحث الثالث: معدلات البطالة والجرية في إقليم كوردستان العراق في 2017 1.4 معدلات البطالة في إقليم كوردستان العراق في 2017}

نتيجة للحرب الضروس التي نشأت بين قوات الإقليم وإرهابي داعش، فقد تعثرت قاطرة التنمية في الإقليم وزادت نسب البطالة، في ظل تخصيص 40 \% من ميزانية الإقليم للنواحي العسكرية، كما زاد عدد اللاجئين في الإقليم سواء الفارين من الدمار الواقح في سوريا أو الفارين من المناطق العراقية التي وقعت تحت سطوة الدواعش، وفي ظل تقليص الدئ الحكوي للنتمية، سواء من الحكومة
كوردستان، والتي تم جمعها بالتعاون مع منظمة "راند" الأمريكية عام 2012، فإن 38.4 من سكان إقليم كوردستان تتزاوح أعهارهم بين 15 إلى 64 سنة، مسجلون بالقوة العاملة، ويلغ عددهم مليون و296 ألف و701 شخص، ومن بين هذا العدد، هناك 7.9\% بلا عمل ـ وأسهم النمو الاقتصادي في إقليم كورستان عام 2013، في خفض معدل البطالة بنسبة 6.5\%، ورفع معدل التوظيف بنسبة 39.8، وبلغ عدد القوة العاملة في القطاع العام مليون و339 ألف و687 شخص، من بينه 87 ألف و186 شخصاً فقط بلا عمل (موقع (روواد) العراق مقال بتاريخ 2016/10/5) وقد كان معدل الفقر في عام 2013 يمثل نسبة 13\%، وتعد هذه النسبة متدنية وغير عالية وفقا لماكانت تمر به البلاد من ظروف الاحتلال . وفي دراسة نشرها الجهاز المركزي للإحصاء عن مؤشرات البطالة في محفظات العراق في مقارنة بين عاي 2014 و 2016 ، يتبين لنا زيادة نسب البطالة، وقد كنا قد ذكنا سالفا أن الإحصاءات الحكومية في أحسن الأحوال هي إحصاءات تقريبية لا تعكس الواقع، وذلك لعدة عوامل من أهها إبراز جهود الدولة في القضاء على البطالة، فتشير الإحصاءات إلى أن نسبة البطالة في محافظة أربيل تبلغ 8.3 ويبلغ النشاط الاقتصادي 49.1\% في حين كانت نسبة البطالة في عام 2016م تبلغ 13\% تقريبا وبلغ النشاط الاقتصادي 47.5\%، وفي نظرة سريعة على هذه المقارنة يتبين لنا تأثر النشاط الاقتصادي سلبا بزيادة نسبة البطالة .

\begin{tabular}{|c|c|c|c|c|}
\hline \multicolumn{5}{|c|}{ معدلات البطالة والنشاط الاقتصادي للاعمار 15 + حسب المحافظات للسنوات 20142016 \& } \\
\hline \multirow{2}{*}{ 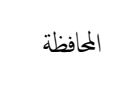 } & \multicolumn{3}{|c|}{ ** 2016} & * 2014 \\
\hline & البطالة & النشاط الاقتصادي & البطالة & النشاط الاقتصادي \\
\hline دهوك & 16.6 & 39.3 & 8.8 & 42.3 \\
\hline نينوى ( إن & -- & -- & 8.2 & 39.2 \\
\hline 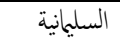 & 10.2 & 43.6 & 5.7 & 45.7 \\
\hline كروك & 9.9 & 39.8 & 2.9 & 46.0 \\
\hline 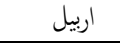 & 13.6 & 47.5 & 8.3 & 49.1 \\
\hline ديالى & 5.7 & 41.1 & 8.8 & 39.7 \\
\hline \multicolumn{5}{|c|}{ "نائُ المسح الاجتماعي والاقتصادي للاسرة في العراق لسنة 2014} \\
\hline & لَ لسنة & شاشة للاسرة في الع & لمة التغذوي & **نائُ مسح تقويم ا. \\
\hline
\end{tabular}

تم اختصار البيان ، وحذف بعض البيانات غير المطلوبة في هذا البحث (موقع وزارة التخطيط - الجهاز المركزي للإحصاء)

2.3 معدلات الجريمة في إقليم كوردستان العراق قبل 2013 


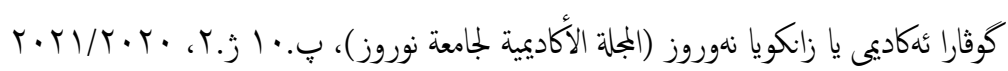

استبعاد المنتحرين من النساء بدافع الشرف يتضح لنا أن العدد المتبقي من المنتحرين هو لشباب فقدوا أو ئسوا من الحصول على فرصة عمل. ومن الأدلة على ذلك أن أحد الموظفين الحكوميين تم اتهامه بسرقة حليب لطفله الرضيع، وتم تحوياه للمحاكة، فإذا كان هذا الموظف الذي يتقاضى راتبا شهريا يقدر ب \$250\$ ويعيش في بيت مستأجر ، ولا يستطيع أن يوفر المتطلبات

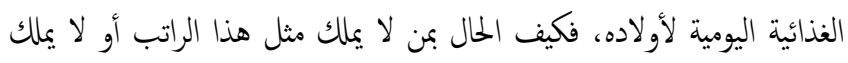

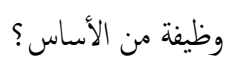

وقال أحد المقربين من الشخص المدان ويدعى سرور أكبر: "حمكة منطقة كرميان أصدرت حكما بحق المواطن بسبب سرقة عدد من علب الحليب وحفاضات الأطفال لابنه الرضيع"..."سوء الأوضاع المالية دفعت المواطن إلى السرقة لتوفير

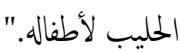

والمتهم موظف في بلدية مدينة كفري منذ 30 عاما براتب 300 ألف دينار (ما يعادل 250 دولار أمريكي)، ولديه أربعة أطفال ويسكن في منزل مؤجر. (موقع رتون لاين : مقال بعنوان ( السجن 11 عاما لعراقي سرق حليب لطفله الرضيع) 5. المبحث الرابع: أثر انخفاض وارثفاع معدلات البطالة على الجرية في إقليم كوردستان مما سبق عرضه يتضح لنا أن معدل الجريمة مرتبط ارتباطا وثيقا بعدل البطلالة في إقليم كوردستان فإذا الخفض أحدها انخضض الآخر وإذا ارتغع أحدها ارتفع الآخر ، وارتبطت الجرائم بالعنف الأسري، والهب والسرقة، والقتل أو الانتحار. فيا قبل عام 2013 كان الإقليم في مرحلة من الاستقرار النسبي، وينعم فيها بكيك ذاتي، ويتم توفير الموارد اللزمة للتنمية وخلق فرص للعمل، وخلال هذه الفترة، كان معدل البطالة يقترب من 7\% ومعدلات الفقر نخو 20\%، وتعد هذه أقل نسبة للفتر منذ حرب تحرير الكويت في عام 1991، إذ عقب هذه الحرب سجلت

معدلات فقر بنسبة وصلت حوالي 90\% في دولة العراق بصفة عامة. وقد عملت حكومة الإقليم منذ تمتعها بالحكى الذاتي؛ عملت على تحقيق نسب نمو، ولهذا السبب كان توفير فرص العمل من أولى أولوياتها، وقد تحقت أهدافها نسبيا في القضاء على البطالة، وقد شهد الإقليم استقرارا أمنيا كيرا، وامتلك عدد من السكان سيارات خاصة بهم، ففي عام 2012 كان متوسط دخل الفرد في الإقليم \$000 وذلك مؤشر قوي لوفرة الفرص المتاحة للقوى العاملة في سوق العمل، ولذا انخفضت معدلات البطالة وانخفض معها معدل الجرائم.
الفيدرالية ببغداد، أو من حكومة الإقليم نفس، نتج عن ذلك ارتفاع نسبة الفقر في الإقليم إلى 30\%. كشف تقرير عن ارتفاع نسبة البطالة في إقليم كوردستان والعراق من 20 في المئة الى 25 في المئة. النسبة الاكبر للبطالة سبلت في اوساط خريجي المعاهد والجامعات والاعداديات، اما النسبة الاقل فقد سجلت في اوساطِ إلميين وغير الحاملين للشهادات. واضاف التقرير الذي اعدته منظمة السلام والحرية بالتعاون مع منظمة الاغاثة الشعبية النوييية إن البطالة في العام 2014 كانت 6.53\% وارتفت في العام 2015 الى 16.56\% فيا ارتغت خلال العام الحلالي 2017 الى مابين 20 الى 25\%، واضاف ان النسبة الاكبر للبطالة خلال عام 2016 سجلت في محافظة دهوك واقلها في السليانية، فيا اوضح ان نسبة البطالة بين اوساط الخرييين وصلت في العام 2015 الى 21\% والذين لايحملون الشهادات 6\% ، كما اشار الى ان اكبر نسبة بطالة سجلت في اوساط حاملي الشهادة الاعدادية وبلغت اكتز من 24 \%، وتخمن وزارة التخطيط ارتفاع معدلات الفقر، خلال العام الماضي، الى 30 \% ، بعد ان سبلت 22\% خلال آخر مسح أجري في العام 2014، وكثفت ان عدد المطلقات والأرامل في عموم العراق بلغ مليوني مطلقة وأرملة تقريباً. وبسبب تناقص الوظائف الحكومية وعدم تمكن القطاع الخاص من تشغيل الهعداد الكبيرة من الايدي العاملة، وارتفاع اعداد النازهين، تثير التوقعات الى ان معدلات البطالة، هي الاخرى، سجلت ارتفاعيرا قد يقترب من 35 في المئة.( موقع ايرو نيوز - مقال : العراق بلد نقطي يتحول إلى بلد بطالة)

\section{4 معدلات الجريمة في إقليم كوردستان العراق في 2017} منذ بدء الحرب على داعش في عام 2014 م ظل معدل الجريمة، يتزايد بصورة مطردة في إقليم كوردستان حتى وصل إلى ذروته في عام 2017 م، حيث كما جاء في إحصاء نشره موقع "نقاش" وقد سبل هذا الإحصاء بمعرفة هيئة حقوق الإنسان في إقليم كوردستان أن عدد القتلى في الإقليم في الفترة من منتصف 2016 إلى منتصف 2017 م وصل لعدد (377) أي بواقع أكثر من حالة يوميا. ومع اختلاف دوافع القتل، وتنوع الحلات ما بين قتل أو انتحار، إلا أنه يعتبر معدلا عاليا يشير إلى عنف مفرط، ولا شك أن مرور الإقليم بأزمات مالية يمثل جانبا ليس بالقليل في دوافع القتل، بل إن وقائع الانتحار وخاصة بين الشباب نستطع أن نعزوها إلى سبب رئس وهو البطالة والمرور بضوائق مالية، إذ لو تم 


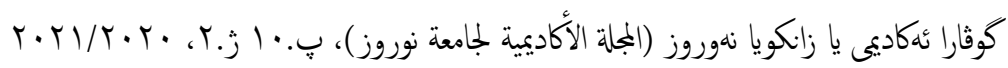

اقتصاديا على الدول والأقاليم من خلال التزام الدول المستضيفة لم بتقديم الخدمات الغذائية والصحية والإسكانية لم. وينج عن ذلك بأن يقاسم هؤلاء النازحون المواطنين الأصليين في فرص العمل وفي الدع المقدم لم من الدولة. التزام الدولة بتوفير فرص العمل الملائمة للمرأة باعتبارها نصف الجنتمع وفي إطار من المحافظة على عادات وتقاليد السكان.

استمرار الدولة في سن القوانين المنظمة للعمل والمحافظة على حقوق العهال وتوفير مظلة تأمينات اجتاعية لم. ضرورة إعادة هيكلة وحوكة أنظمة العمل بالقطاع العام (الحكوي) لخلق فرص عمل حقيقية. العمل على تحويل العالة الموسمية والمؤقتة إلى عالة دائمة. تحديث قطاع الزراعة من خلال ربطه بالقطاع الصناعي عن طريق إنشاء صناعات قائمة على منتجات القطاع الزراعي أو صناعات خدمية للقطاع

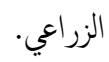
تطوير المنشآت النفطية. ترشيد الإنفاق الحكوي ومكافة الفساد. توفير إمكانية تنقل العامل أو ( طالب العمل) إلى المناطق ذات الوفرة في فرص العمل، ونشر ثقافة التنقل من أجل العمل بين المواطنين. ضرورة تقليص البضائع والسلع المستوردة، وإنشاء مصانع لتصنيعها محليا، فذلك يوفر فرص عمل جديدة ودائمة للمواطنين، ويقلل من مصروفات الاستيراد.

ومن نناجُ البحث أيضا يمكن القول بأن : - - البطالة هي العقبة التي تعيق كل جهود التنمية، وهي الصخرة التي تتحطم

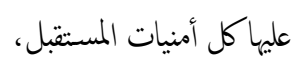
- - مالبطالة هدر للطاقة البشرية ولموارد المالية. - - البطالة والجريمة متلازمتان لا تنفك إحداهيا عن الأخرى. - معالجة آثار البطالة أكثر تكفة من توفير فرص عمل للشباب.
أما إذا استعرضنا معدلات البطالة في عام 2016 فسنجد أنها كانت مرتفعة للغاية

$$
\begin{aligned}
& \text { حيث وصلت إلى حوالي 70\% بسبب عدة عوامل من أهها : } \\
& \text { الخلاف الناشئ بين حكومة الإقليم والحكومة المركزية ببغداد. }
\end{aligned}
$$

$$
\text { هرب المستمرة للقضاء على تنظيم داعش. }
$$

وجود أكثر من مليون ونصف نازح وهجر بالإقليم من العراق وسوريا.

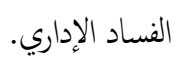

ومن خلال الدراسات السابقة للموضوع المقتح هناك العديد من الدراسات التي تشير إلى النتائُ السلبية والكبيرة للبطالة على معدلات الجريمة ومنها:

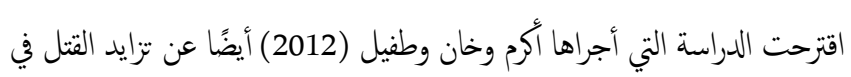
الشوارع والسطو والخطف بسب البطالة. ركزت دراسته على إبراز الشرور التي تسبيها البطالة، كما أظهرت الدراسة أن المحسوبية في السياسة أصبحت أحد أسباب البطالة، غالبًا ما يحرم الشباب من الحصول على وظائف على أساس

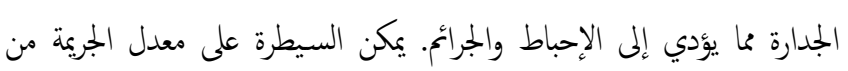
خلال وضع سياسات عادلة في البلاد حتى لا يحرم أحد من حقه. يجب على واضعي السياسات تحليل السكان والحاجة إلى العمل من قبل الشباب. ينبغي أن تعكس الخطط الاقتصادية للبلدان النامية بوضوح احتياجات العمالة لشبابها.

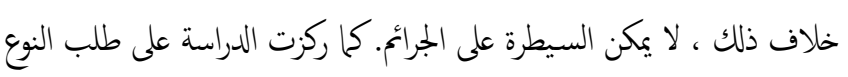

$$
\text { المناسب من التعليم للثباب حيث أنها ستوبحمم لاختيار المسار الصحيح. }
$$

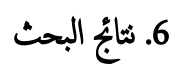

تتأثز البطالة إيحابا أو سلبا بالحالة الأمنية للإقليم، فكلما انضبطت واستقرت الحالة الأمنية كلما انخضضت نسبة البطالة، وكثرت فرص العمل المثاحة

$$
\text { وارتنغ نصيب الفرد من النانج القوي. }
$$

دور القطاع الخاص أصبح ضرورة، وعليه مسؤولية تجاه الوطن في ضرورة التخفيف من حدة البطالة عن طريق الاعتماد على الأيدي العاملة الوطنية وتوفير مناخ من الأمن الوظيفي للعامل. تتثأز الدول بعدم الاستقرار السياسي أو الفوضى التي تنتشر لدى جيرانها، وتكون الأقاليم الحدودية كبش الفداء وتدف ضريبة الحروب الأهلية عند استقبالها أعدادا كبيرة من النازهين، في ظل وجود اعتمادات مالية ضعيفة، وتنصل الجمتع الدولي من تقديم مساعدات لهؤلاء النازحين مما يجعلهم عبئا 
- - ميث إن هذه النوعية من العمال تكون لديهم الرغبة في العمل ويمتلكون المهارات اللازمة، لذلك يكون تعطلهم عن العمل له ننائج أشد ضراوة

وقساوة عليهم.

- 7 مقتزهات

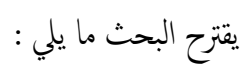

وجود مؤسسات حكومية تسعى قُدما لإيجاد حلول لمشكلة البطالة.

$$
\text { العمل على خفض معدلات الجرائ. }
$$

تكليف الباحثين بإعادة دراسة الظواهر الاجتاعية لإيجاد الحلول الملائمة من

$$
\text { منظور علمي. }
$$

زيادة الوعي الثثقيفي للشباب من خلال حملات التوعية والندوات

والمحاضرات.

$$
\text { دمج الشباب في العمل المجتمي والسياسي بصورة أكبر. }
$$

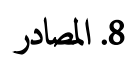

1. مجموعة من الباحثين والمؤلين - الموسوعة العربية العلمية (1999)، الموسوعة العربية

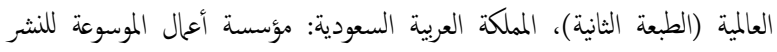

والتوزيع. 2. إخلاص فاضل، فراس بدر، حسن علي، (2012) ، مشكلة البطالة عند الشباب،

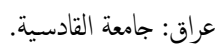
3. مركز الإمارات للسياسات - مقال (إدراج العراق في اللائحة الأوروبية للدول عالية

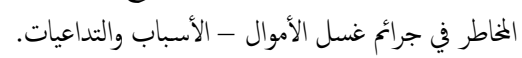
4. فتحية باحشوان (2017)، الشباب والبطالة، يمن: جامعة حضرموت.

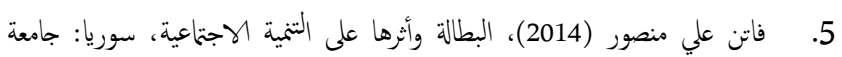
تشرين. 6. حنان عبدالخضر هاشم وآخرون"البطلالة في الاقتصاد العراقي الآثار الفعلية و المعلجات

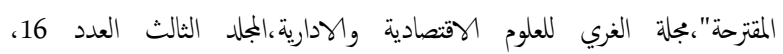
87 2010 د. كامل علاوي كاظم،البطالة في العراق، الواقع الآثار آليات التولد وسبل المعالجة،جامعة الكوفة،كلية الإدارة والاقتصاد، 2011 .

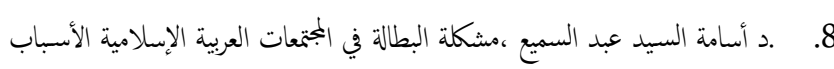

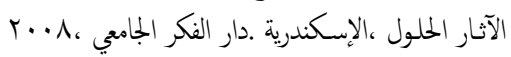

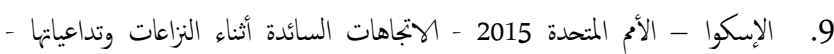

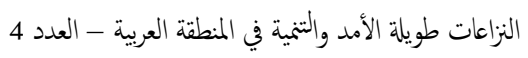

\section{0. مواقع الكترونية} 1. إموق (رووادو) العراق - مقال بتاريخ 2016/10/5 م. 2. موقع وزارة التخطيط - الجهاز المركزي للإحصاء.
- - الشباب هم أمل كل أمة، واستثمار قدراتهم وطاقتهم هو الاستثمر الأمثل

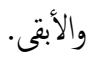
- ت تحيق التنمية المستدامة مرهون بالتدريب والتغير مع متغيرات العصر. - - الجريمة في الغالب ناشئة عن البطالة والقضاء على البطالة هو قضاء على

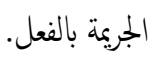

الشبابية، وفي استثار الموارد الطبيعة المتاحة في الإقليم للتحول الصناعي. للانضام إلى الجماعات المتطرّفة، فن السهل إقناعهم بأهداف هذه الجماعات،

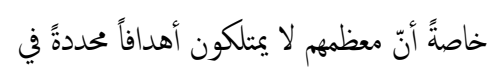
- حياتهم، فيعتبرون كلاً من التطرّف، والعنف طريقة للتّعبير عن الذّات. - - الهجرة: إن عدم القدرة على إيجاد حلولٍ لمشكلة البطالة، أجبرت الكثير من الشباب على التفكير بالهجرة إلى خارج البلاد لاييجاد فرصة عمل. (باحشوان (2017) - (17) - كما أن تفثي البطالة داخل الأسرة التي تعد المؤسسة الاجتاعية المسؤولة عن تنشئة جيل قائم على المبادئ والقيم، سيكون لها أثر سلبي بسبب

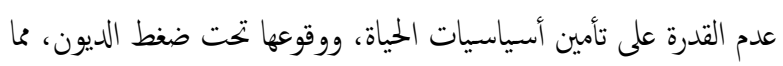
يؤدي إلى زيادة التوتر النفسيّ لعدم القدرة على سدادها، وفي بعض الأحيان قديجبر الأبناء لدخول سوق العمل وهم في سنّ الدراسة، مما يؤدي إلى ظهور الاضطرابات التي تؤّبّ عليه سلباً. من ذوي الاحتياجات الخاصة من أصحاب الهمم ( المعاقين ) يمثلون تحديا بالغا للحكومات في توفير

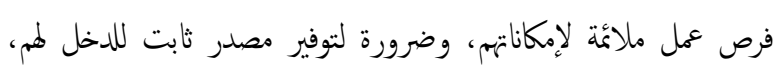

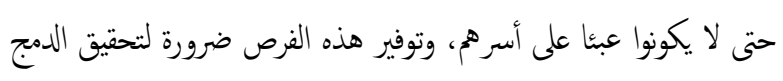
بين ذوي الاحتياجات الماصة وباقي أفراد المتمع.(منصور - 2017 - 97) - - - إن أصعب أنواع البطالة هي البطالة الإجبارية وهي التي يتعرض لها من فقد عمله رغا عنه، وقد عانى كثير من أبناء الإقليم من هذا النوع بسبب تسريح عدد كبير من العمال في أثناء الحرب على داعش. 


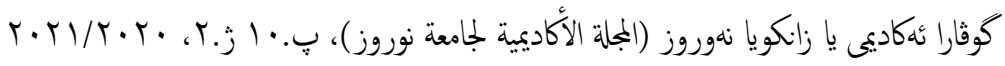
3. موقع ايرو نيوز - مقال : العراق بلد نقطي يتحول إلى بلد بطالة. 4. موق رتون لاين : مقال بعنوان ( السجن 11 عاما لعراقي سرق حليب لطفاه الرضع).

11. مصادر الاجنبية

1. Ajimotokin, S., Haskins, A., \& Wade, Z. (2015). The Effects of Unemployment on Crime Rates in the US.

2. Samuelson, Paul, 1977 ((Economics)), New York, Mc Graw Atill Book Co, P. 243. 